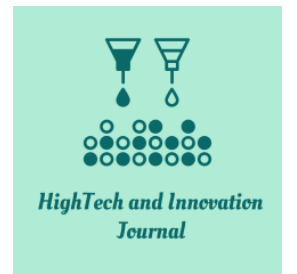

ISSN: $2723-9535$

\title{
The Performance of a Cross-flow Turbine as a Function of Flowrates and Guide Vane Angles
}

\author{
Anthony A. Adeyanju ${ }^{1 *} \odot$, K. Manohar ${ }^{1}$ \\ ${ }^{1}$ Department of Mechanical and Manufacturing Engineering, The University of the West Indies, St Augustine, Trinidad and Tobago.
}

Received 13 September 2021; Revised 09 December 2021; Accepted 11 January 2022; Published 01 March 2022

\begin{abstract}
This study looked at the effects of flow rates and guide vane angles on the performance of a cross flow turbine, which can be used to generate energy and hydraulic power with low head and low flow rates of water. A fluid dynamic analysis was performed on the cross-flow turbine with the aid of finite element techniques. The simulation was solved after validating the convergence of the provided model and its boundary conditions, with the outputs being the velocity profiles of the flow in the rotor and the pressure distribution on the rotor surface during its rotations. Experimental evaluation of the cross-flow turbine guide vane positions at a flow rate of $0.8,0.6$, and $0.5 \mathrm{~m}^{3} / \mathrm{s}$ was conducted, and it was discovered that a maximum turbine speed of $482 \mathrm{rpm}$ and a generator speed of $1920 \mathrm{rpm}$ were produced at the rotor shaft at a flow rate of $0.8 \mathrm{~m}^{3} / \mathrm{s}$ with a head of $25 \mathrm{~m}$, and this data was validated by the results produced from the simulation.
\end{abstract}

Keywords: Crossflow Turbine; Guide Vane Angles; Flowrate; Hydraulic Power; Turbine Speed.

\section{Introduction}

The impulse turbine is a development of the simple stream wheel, which uses the natural flow of water to power the rotor. In contrast to the stream wheel, which is powered by the natural flow of water, an impulse turbine created at a high height is powered by a strong jet of water [1,2]. The ratio of static pressure drop in the rotor to static pressure drop in the stator or nozzle plus the rotor $[3,4]$ is the degree of response, which is defined as the differential in the pressure drop between the nozzle and the rotor. Impulse turbines work by a high-velocity jet exerting force on the rotor blades, with the nozzle converting all of the potential energy into kinetic energy before the flow passes through the blades. Because of the dynamic pressure difference generated by the two surfaces of the blades, the momentum of the jet of water is removed by the blades, but the static pressure differential across the surface atmosphere is maintained, giving the impulse turbine with zero responses.

Pelton turbines are an example of impulse turbines that have a series of spoon-shaped buckets erected at the wheel's periphery. The buckets are created in such a manner that they force the entering water to change course and escape from the other side while transmitting its energy to the wheel. Reaction turbines, on the other hand, have a degree of reaction since they operate on the idea of reaction forces developing across the rotor blade's surface. In the principal source for the angular momentum extraction, pressure decreases between the impeller blades and staticguiding vanes. In contrast to impulse-based design fluid that is released from a nozzle that is directly in contact with the impeller, pressure loss occurs in both the rotor and nozzle of a reaction-based turbine [5]. When the discharge medium exits the nozzle at a high velocity, it generates a reactive force that causes the impeller to rotate in the

* Corresponding author: anthony.adeyanju@sta.uwi.edu

$>$ This is an open access article under the CC-BY license (https://creativecommons.org/licenses/by/4.0/).

(C) Authors retain all copyrights. 
opposite direction of the discharged fluid, creating suction via the draft tube in the casing. A spiral type intake in the casing of a reaction turbine frequently incorporates control barriers to control the flow of water. Suction is generated through the draft tube in the casing when the discharge medium exits the nozzle at a high velocity, creating a reactive force that drives the impeller in the opposite direction of the discharged fluid.

A spiral type intake in the casing of a reaction turbine is frequently used to regulate the flow of water. The CrossFlow turbine, which is a form of impulse turbine, is one of these types of water production systems. The impacts of various geometric factors on the overall efficiency and power output of the turbine were investigated [6]. Various factors, such as the number of blades attached to the rotor, the angle of attack of water on the rotor blades, and ultimately, modifications in the inner to outer diametric ratios, were all part of the studies. The experimental run showed that the system's efficiency improved as the number of blades rose, but that increasing the angle of attack beyond 24 degrees did not add to the increase in efficiency. Furthermore, it was discovered that when the number of runners in the arrangement was retained at 27, the combination of a 24-degree angle of attack and a diametric ratio of 0.68 produced the highest efficiency. Further research revealed that as the inner to outer diametric ratio was changed between 0.6 and 0.75 , increasing the attack angle resulted in a loss in efficiency.

Experimental research [7-10] investigated the impact of the aspect ratio of the rotor diameter and the span of the blade on a cross-flow turbine. Because of the limited interaction of the blade support, the study determined that the operational effectiveness of the turbine depends on a combination of Reynolds and Froude numbers. The coefficient of effective operation was found to be unalterable, given the values of aspect ratios investigated. An experiment was conducted in which three types of turbine nozzle roof curvature were used to study the features of cross-flow turbines [11]. The experiment revealed that as the length of the entry arc of the nozzle decreased, the optimal efficiency regions expanded, and as the length of the entry arc of the nozzle increased, the best efficiency points decreased, confirming that the optimal efficiency of the cross-flow system was achieved when the entry arc of the nozzle was at 75 and 90 degrees, respectively. To increase the turbine efficiency, nozzles with the roof curvature centered on the axis of the rotor shaft should be used, and nozzles with an arc entrance angle of 120 should be used when there is a fluctuation in the load and hydro-potential system.

Two-dimensional computer simulations were used to show that linear nozzles offer a constant angle of attack on water [12]. The authors proved that the energy losses on the impeller's inner side are low. Further research revealed that while the number of blades and diametric ratio have no influence on the characteristic curve, they do reduce the turbine's efficiency. The rotor rotational speeds at a constant flow rate were used to simulate load conditions on the turbine shaft; higher rotor rotational speeds represent low load conditions, while lower rotor rotational speeds represent increased torque loads on the turbine shaft [13].

This study looked at the effects of flow rates and guide vane angles on the performance of a cross flow turbine, which can be used to generate energy and hydraulic power with low head and low flow rates of water, in contrast to large-scale power plants that use vast reservoirs of water to generate energy.

\section{Simulation of the Cross-flow Turbine}

With the aid of a Finite Element Model (FEM), a combination of structural and fluid dynamic analysis was performed in this study. In circumstances where a complete knowledge of any physical phenomenon based on its mathematical models is required, the application of FEA is critical. The bulk of these behaviours could be predicted using partial differential equation techniques in cases when structural, thermal, or fluid behaviour must be examined. The purpose of using simulations was to investigate the rotor's static structural behaviour, analyse the system's natural frequency under the rpm produced by the flow of water, and investigate the system's harmonic response under operational conditions. The simulations were performed to investigate the characteristics and behaviours of the crossflow turbine under the input conditions of flow rate and head of water. The fluid dynamics were studied in this analysis, with the velocity distribution profile and pressure distribution within the turbine housing, as well as the flow pattern exhibited by the fluid.

\subsection{Cross-flow Turbine Design Analysis}

SolidWorks 2019 [14] was used to create the CAD models, which were scaled to $1: 1$ and assembled to validate the concepts. Each component was built in SolidWorks assembly modeller using the necessary mates and fits, and the rotor and turbine housing were assembled as designed. The modelled rotor and turbine geometries were converted to step format for them to be loaded into the Ansys Design [15] modeller without losing any parametric data. Separate parameters and named choices were established based on the distinct surface to surface and surface to fluid interactions predicted in the simulation after the rotor and housing models were imported into separate design modeller modules. The two distinct surface interactions define the turbine. The Mesh modeller was used to create optimal meshes from the supplied models. After meshing and defining the model, it was imported into CFD pre, 
where input parameters and boundary conditions were set, and simulations for the given conditions were solved. Following a successful solution, the CFX solve outputs were used as inputs to the simulation's static structural module.

To assess the structural integrity of the rotor and shaft at the specified rpm and loads imposed by fluid during the rotation of the rotor under the flow rate of fluid in the turbine housing, the load applied to the rotor and rotor shaft was simulated. The CFX solver package was used to compute the loads. The static structural module's findings were utilised as the basis for modal and harmonic analysis. SolidWorks software was used to do parametric modelling for the cross-flow turbine study. The model consisted of two parts: the turbine housing with the nozzle and the turbine rotor, which was used to complete the study. After preparation, the models were converted to step file format and loaded into Ansys. Figure 1 shows the cross-flow turbine CAD model produced by Ansys for CFD and structural analysis. The design was created to make the assembly easier by using real size clearance, as shown in the CAD drawings.

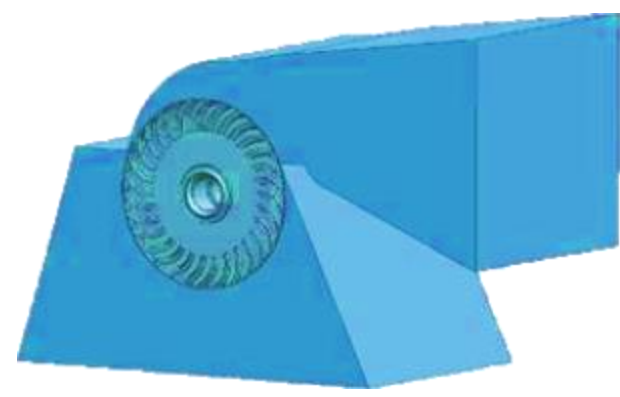

(a)

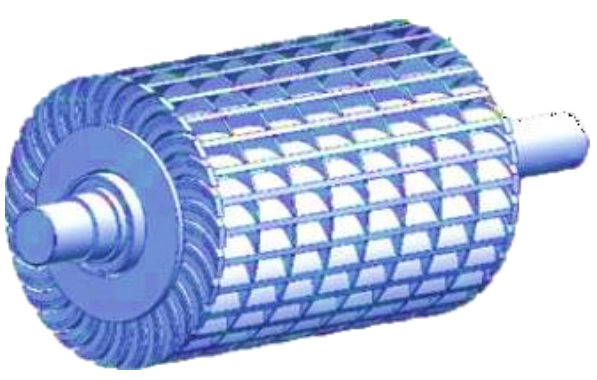

(b)

Figure 1. The CAD models prepared for CFD analysis: (a) Turbine Housing; (b) Rotor

To assign geometric and meshed parameters, the rotor and turbine housing models were loaded into two Ansys design modeller modules. For this study, the nozzle and turbine housing are regarded as stationary domains, while the rotor is characterized as a revolving domain that rotates at a set number of RPMs. The imported models were divided into several areas depending on their features. The intake region of the nozzle was designated as the inlet, while the outflow region was defined as the outlet. The region between the rotor and the involute of the turbine housing was dubbed the Rotor Volute Interface as an interaction surface between the rotor and the turbine housing. Material properties were allotted to the components based on engineering data. After establishing the geometric attributes of the CAD models in the design modeller, the turbine housing and rotor design modeller modules were coupled with their respective meshing modules, where specific meshing characteristics for each component were established. To attain finer precision, hexahedral mesh nodes were chosen for the study, and the mesh element size was fixed at $6 \mathrm{~mm}$, as shown in Figure 2.

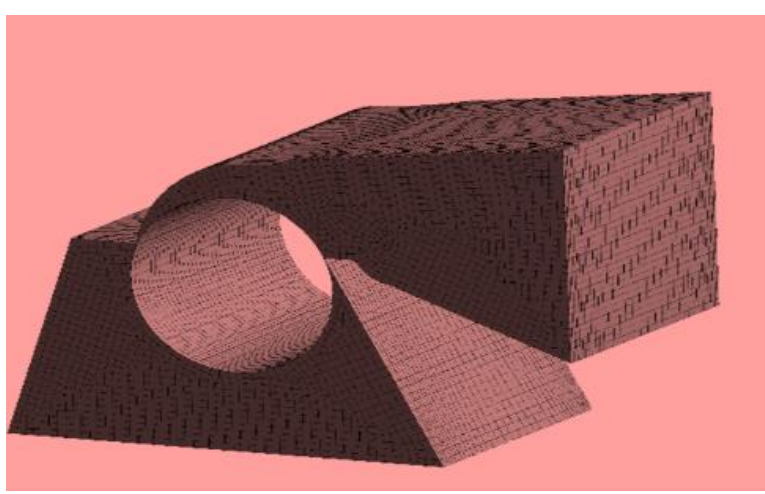

(a)

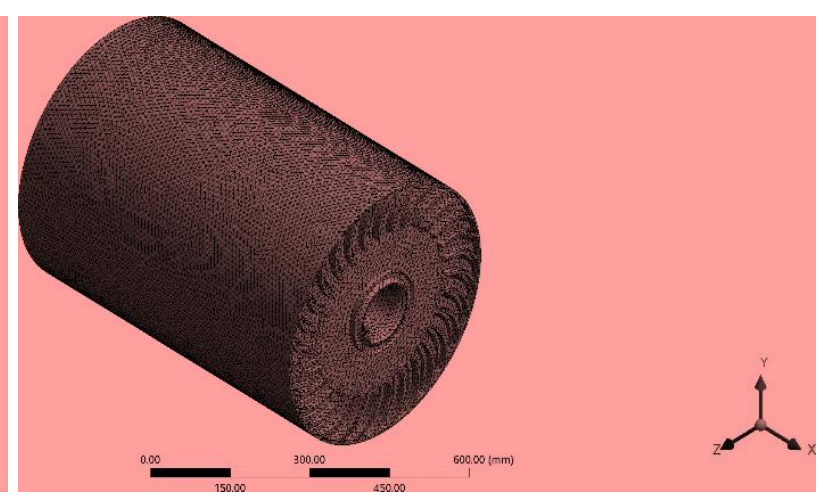

(b)

Figure 2. The Meshed of Turbine Housing and Rotor: (a) Turbine Housing; (b) Rotor

\subsection{Physical Setup and Analysis for CFX}

These geometries were connected with the CFX module of Ansys once the meshes for turbine housing and rotor geometry were created. The k-epsilon turbulent model with scalable wall function was used for this study, as illustrated in Figure 3. 


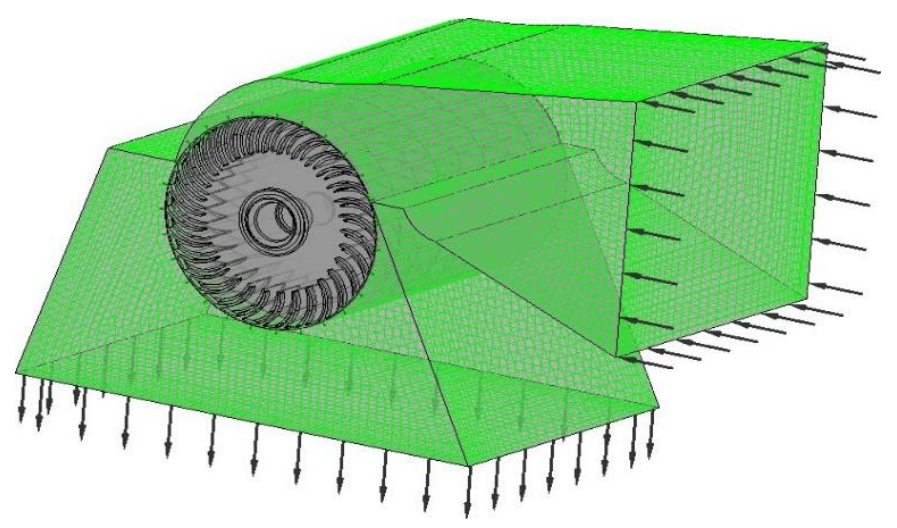

Figure 3. CFX set up of the Turbine Housing

The domains were split into two groups depending on their nature: a stationary domain for the turbine housing and nozzle, and a rotational domain for the rotor. Water was used as the model's working material. The reference pressure is zero, and the boundary conditions are given as absolute numbers. The ambient operating temperature was established and a relative pressure of $345 \mathrm{kPa}$ equivalent derived from the head of water was supplied at the boundary inlet. As atmospheric pressure, the outflow boundary condition was set to 1 bar. For the rotor domain, the rotor geometry was created as a rotary domain using the domain motion option in the analysis setup, with an input angular velocity of $484 \mathrm{rpm}$ and a no-slip smooth wall boundary condition established for all interaction interfaces.

The frozen rotor interface model was defined as the interface between the rotor and the case, also known as the Rotor volute interface. The mass flow rate at the inlet and mass flow rate at the exit of the casing was used as expressions in the study. The solver settings were set to high resolution and configured in the solver analysis tab. With a timeframe factor of 1.00, the simulation's maximum iterations were retained at 400, and the convergence criterion was set at 1e-06. The output control was programmed to track the expression of mass in the system as well as mass leaving the system.

\subsection{Simulation}

The simulation was solved after validating the convergence of the provided model and its boundary conditions, with the outputs being the velocity profiles of the flow in the rotor and the pressure distribution on the rotor surface during its rotations. Figure 4 shows the simulation's output.

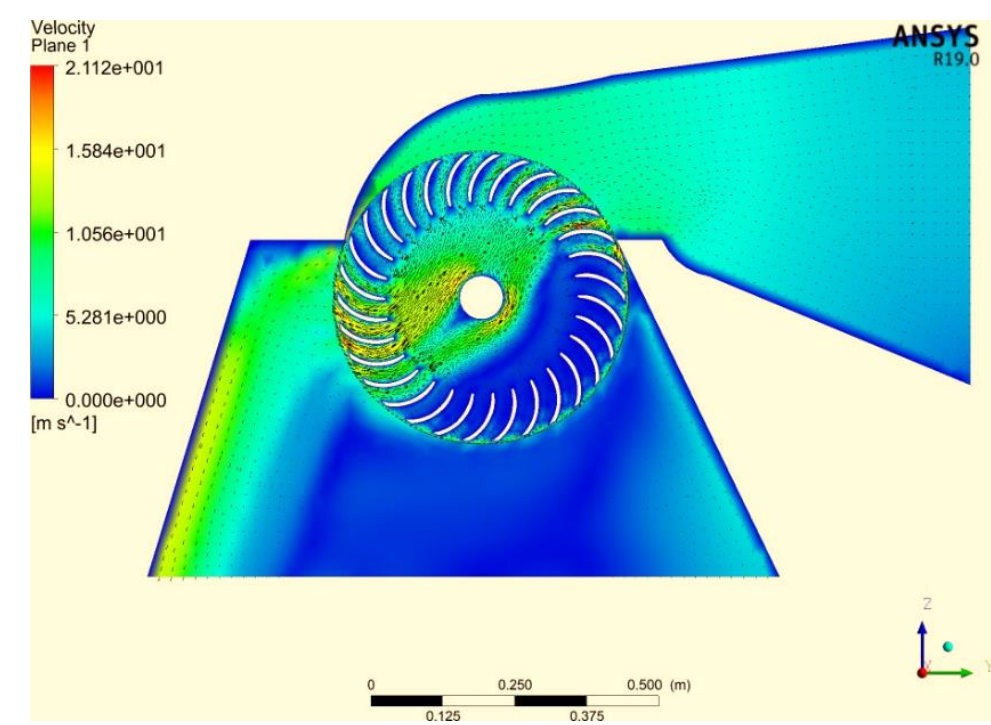

Figure 4. The first and second stages of water contact with the turbine rotor are shown in this velocity profile of water flow

The mass flow within the turbine is equal to the mass coming out of the turbine housing, as shown by the output monitor expressions, implying that the solution has converged successfully and that the boundary conditions do not conflict with the stated solution models. Water enters the rotor and the first stage goes through one set of blades, imparting momentum to the system for the rotor rotation. After passing through the first stage, the second stage imparts momentum to the second area of the blades during the second stage interaction with the rotor. Under the stated boundary condition, Figure 4 illustrates how the pressure profile on the rotor's surface was generated. It is the pressure exerted on the turbine's rotor due to water flowing from the guiding nozzle towards the turbine. 


\section{Experimental Evaluation of the Cross-flow Turbine Guide Vane Positions at Varying Flow Rates}

This section shows the setup of the cross-flow turbine to evaluate its performance parameters and gather experimental data. The following arrangements were made at the test location for experimental assessment;

- For the water source, a 25-meter-high water supply tank was used.

- The intake penstock of the cross-flow turbine was connected to the 8-inch pipeline.

- An 8-inch gate valve was put on the flow pipe to regulate the water flow.

- A foundation was built to secure the turbine during operation, with a base frame installed at the bottom of the turbine's support structure.

- A water channel was built to divert water away from the turbine housing's outflow, and the water was returned to the undersea tank, where it was recirculated to the above supply tank through pumps.

The inlet pipeline was linked to the inlet of the penstock using a specific design adapter that gradually increased the area on the inlet pipe to match the inlet size of the penstock nozzle, and both of these connections were done using slip-on flanges made of Steel plates as shown in Figure 5.

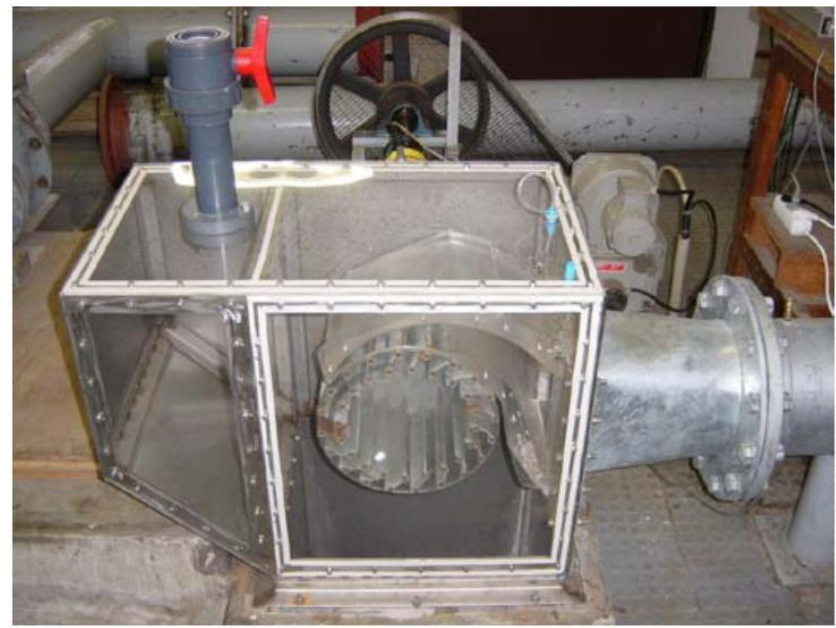

Figure 5. Setup of a cross-flow turbine for performance analysis

The rotor shaft was connected to a pulley and belt system for this experiment. The pulley's weight was maintained low enough that it also served as the assembly's flywheel, regulating and stabilising the power output to the generator from the cross-flow turbine. The power plant's rotor shaft was connected to a flywheel pulley using a flexible coupling that is designed for usage in areas where the system is subjected to axial and torsional stress. The test calculating the flow rate of water from the intake pipe to the cross-flow turbine, measuring the turbine and generator pulley's revolutions per minute, and adjusting guide vane locations with the aid of the guide vane regulator valve. The flow rate was kept constant while the guiding vane was changed in three distinct locations. The experiment was then repeated, with varied values of RPMs achieved for different flow rates received by the turbine rotor.

\section{Results and Discussion}

Tables 1, 2 and 3 show the variation in speed at the turbine shaft and transmitted speed towards the generator shaft for $0.8,0.6,0.5 \mathrm{~m}^{3} / \mathrm{s}$ water flow rates and guide vane position of 45 degrees, mean position and -45 degrees.

Table 1. Positions of the guide vanes at a flow rate of $0.8 \mathrm{~m}^{3} / \mathrm{s}$

\begin{tabular}{cccc}
\hline Head (m) & Guide Vane Position (degree) & Turbine Speed RPM & Generator Speed RPM \\
\hline 25 & +45 & 442 & 1660 \\
25 & Mean Position & 482 & 1920 \\
25 & -45 & 450 & 1772 \\
\hline
\end{tabular}

Figure 6 shows the turbine and generator speed against 3 positions of guide vanes at the water flow rate of 0.8 $\mathrm{m}^{3} / \mathrm{s}$. The turbine speed of $482 \mathrm{rpm}$ and the generator speed of $1920 \mathrm{rpm}$ was discovered at the mean position of the guide vanes as shown in Table 1 . 


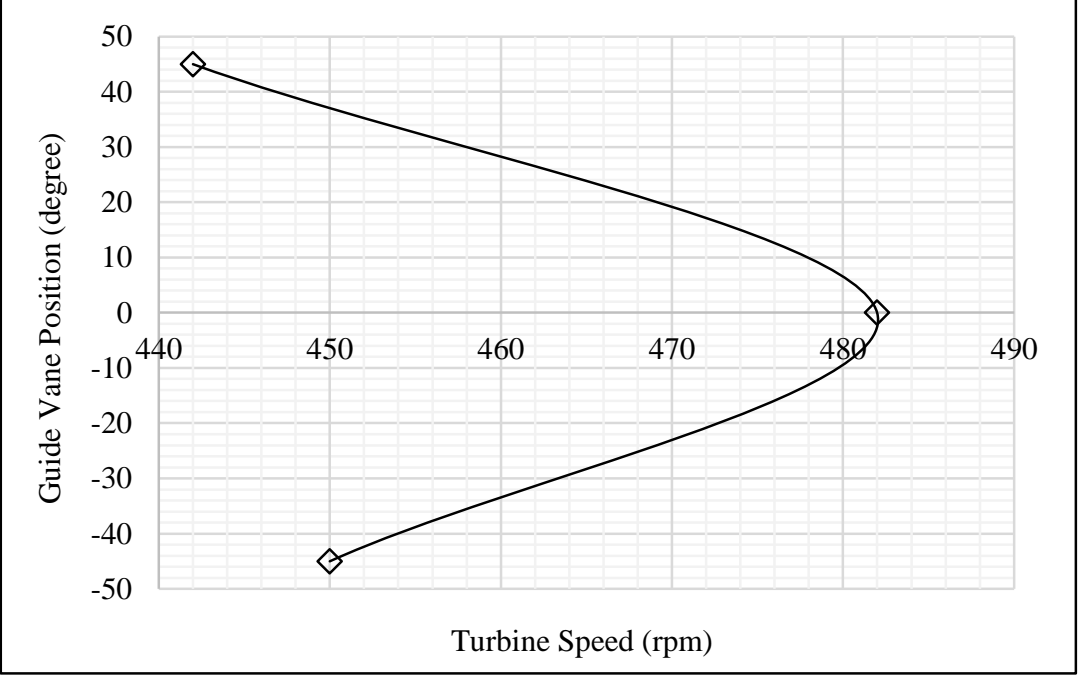

Figure 6. Turbine speed against 3 positions of the guide vane at $0.8 \mathrm{~m}^{3} / \mathrm{s}$

Table 2. Positions of the guide vanes at a flow rate of $0.6 \mathrm{~m}^{3} / \mathrm{s}$

\begin{tabular}{|c|c|c|c|c|}
\hline Head (m) & Guide & Vane Position (degree) & Turbine Speed RPM & Generator Speed RPM \\
\hline 25 & & +45 & 322 & 1020 \\
\hline 25 & & Mean Position & 372 & 1420 \\
\hline 25 & & -45 & 333 & 1230 \\
\hline
\end{tabular}

Figure 7 shows the turbine and generator speed against 3 positions of guide vanes at the water flow rate of 0.6 $\mathrm{m}^{3} / \mathrm{s}$. The turbine speed of $372 \mathrm{rpm}$ and the generator speed of $1420 \mathrm{rpm}$ was discovered at the mean position of the guide vanes, as shown in Table 2.

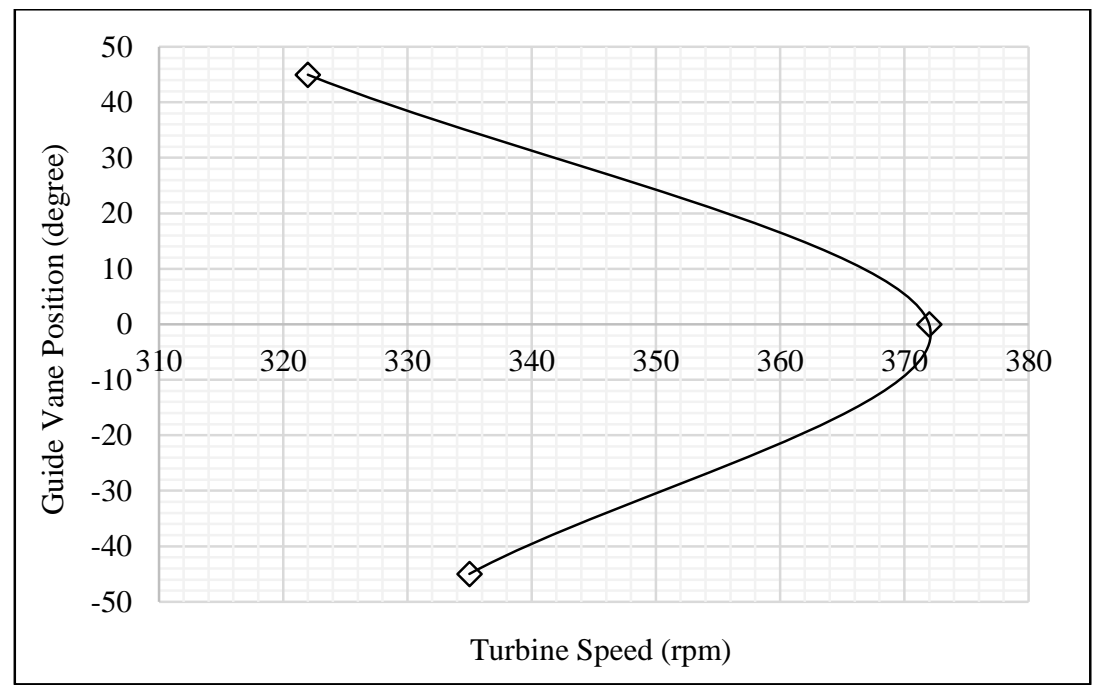

Figure 7. Turbine speed against 3 positions of the guide vane at $0.6 \mathrm{~m}^{3} / \mathrm{s}$

Fig. 8 shows the turbine and generator speed against 3 positions of guide vanes at the water flow rate of $0.5 \mathrm{~m}^{3} / \mathrm{s}$. The turbine speed of $256 \mathrm{rpm}$ and the generator speed of $1016 \mathrm{rpm}$ was discovered at the mean position of the guide vanes as shown in Table 3.

Table 3. Positions of the guide vanes at a flow rate of $0.5 \mathrm{~m}^{3} / \mathrm{s}$

\begin{tabular}{|c|c|c|c|c|}
\hline Head (m) & Guide & Vane Position (degree) & Turbine Speed RPM & Generator Speed RPM \\
\hline 25 & & +45 & 208 & 820 \\
\hline 25 & & Mean Position & 256 & 1016 \\
\hline 25 & & -45 & 217 & 860 \\
\hline
\end{tabular}




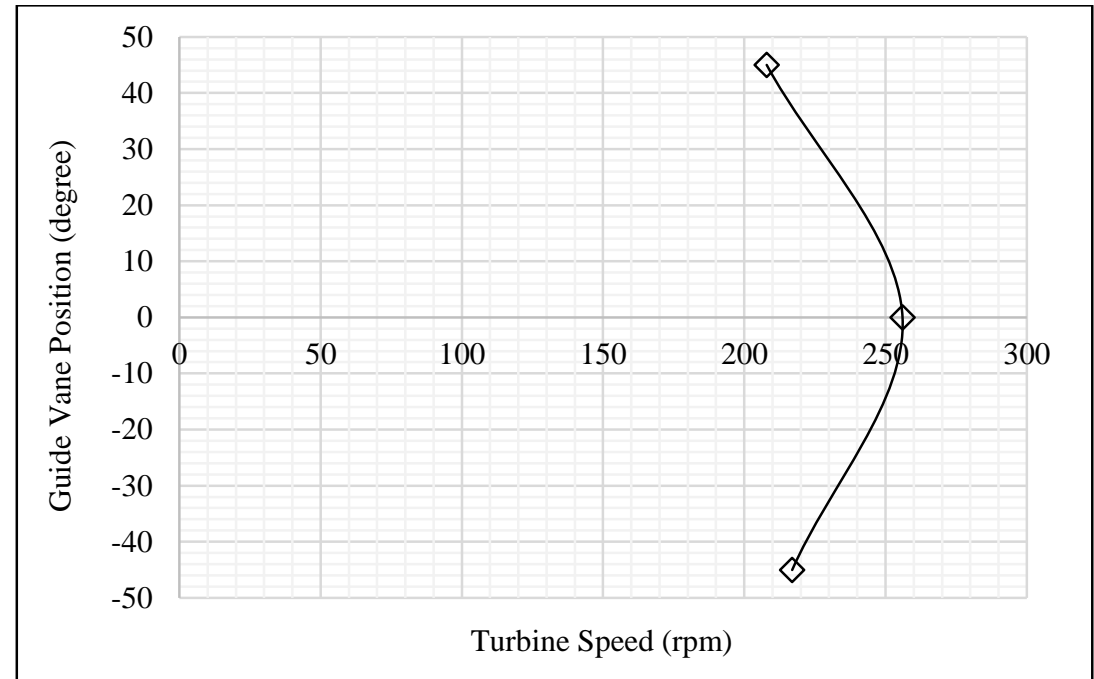

Figure 8. Turbine speed against 3 positions of the guide vane at $0.5 \mathrm{~m}^{3} / \mathrm{s}$

Figure 9 shows the relationship between water flow rates and turbine speed at different guide vane angles. The maximum turbine speed of $484 \mathrm{rpm}$ was generated when the guide vane was orientated at the mean position, while the minimum turbine speed was generated when the guide vane was orientated towards +45 degrees.

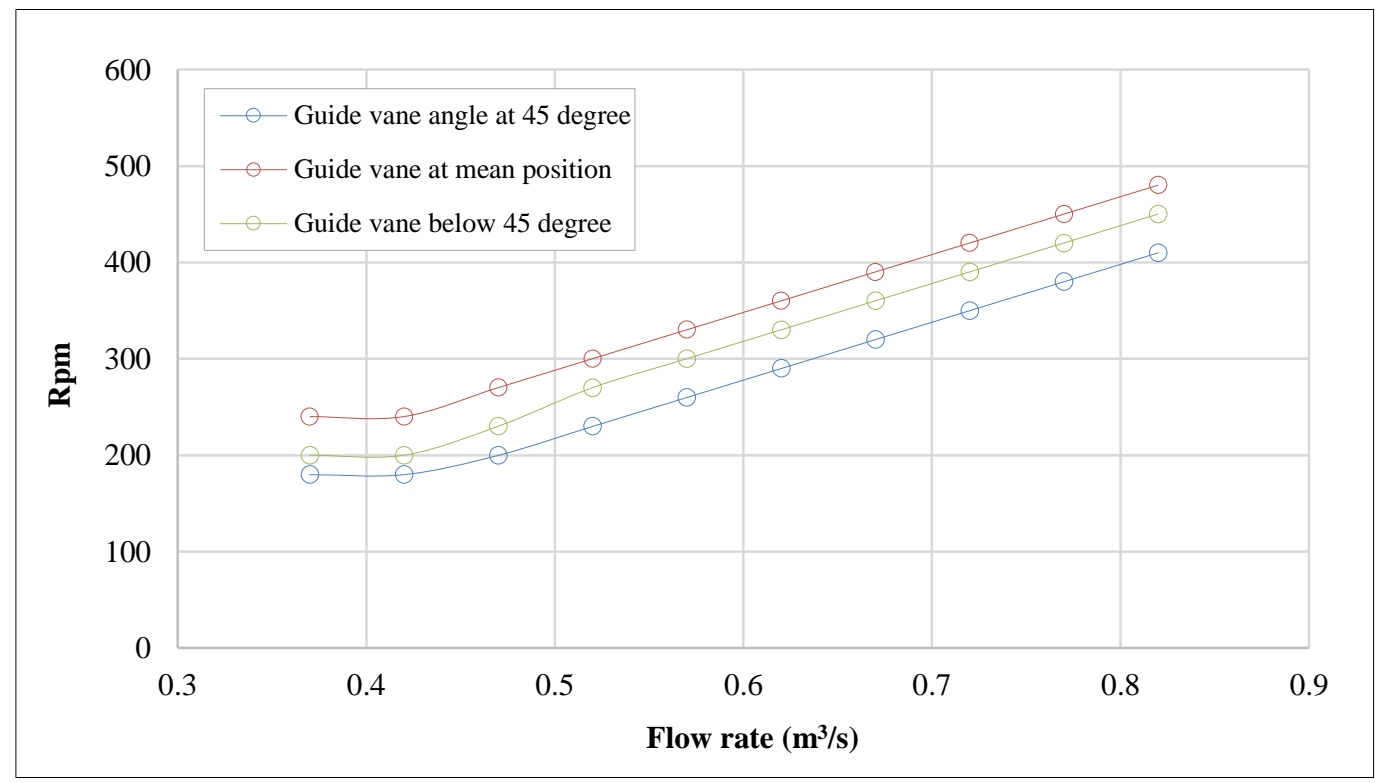

Figure 9. Relationship between flow rate and the turbine speed at different guide vane angles

In contrast to the turbine speed of $484 \mathrm{rpm}$ generated from the CFX results, the experimental maximum turbine speed of $482 \mathrm{rpm}$ was attained at flow rates of $0.8 \mathrm{~m}^{3} / \mathrm{s}$. This discrepancy can be ascribed to losses that emerge owing to mechanical variation in the manufacture of the cross flow turbine. The little discrepancy between experimental and CFD results might be attributable to the loss assumption, which is generally not included in flow analysis. The portrayal of these sorts of flows in turbines will be considerably more realistic if boundary conditions are refined to include far a more comprehensive energy conversion by addressing mechanical behaviours of components.

\section{Conclusion}

The cross flow turbine in this study was installed with a water head of $25 \mathrm{~m}$ and a maximum flow rate of $0.8 \mathrm{~m}^{3} / \mathrm{s}$ to produce $250 \mathrm{~kW}$ of generator power when the runner diameter of $500 \mathrm{~mm}$ was used. The result of this research was in line with the work done by Yi et al. (2018) [16] and Kpordze and Warnick (1983) [17]. Five intermediate supporting discs were used to support the runner, and they provided the design with enough strength to withstand the incoming flow of water at the turbine speed of $484 \mathrm{rpm}$. A generator consisting of 16 synchronous poles was used for the production of energy from the speed produced at the rotor shaft. The speed produced at the rotor shaft was directly related to the increase in flow rates of water up to the maximum flow rate achievable at the site available and was related to the change of the guide vane position at different angles. 


\section{Declarations}

\subsection{Author Contributions}

Conceptualization, A.A.A., and M.K.; methodology, A.A.A. and M.K.; writing — original draft preparation, A.A.A. and M.K.; writing - review and editing, A.A.A. and M.K. All authors have read and agreed to the published version of the manuscript.

\subsection{Data Availability Statement}

The data presented in this study are available on request from the corresponding author.

\subsection{Funding}

The authors received no financial support for the research, authorship, and/or publication of this article.

\subsection{Declaration of Competing Interest}

The authors declare that they have no known competing financial interests or personal relationships that could have appeared to influence the work reported in this paper.

\section{References}

[1] Ghimire, A., Dahal, D., Kayastha, A., Chitrakar, S., Thapa, B. S., \& Neopane, H. P. (2020). Design of Francis turbine for micro hydropower applications. Journal of Physics: Conference Series, 1608(1), 12019. doi:10.1088/1742-6596/1608/1/012019.

[2] Ghimire, A., Dahal, D. R., Pokharel, N., Chitrakar, S., Thapa, B. S., \& Thapa, B. (2019). Opportunities and Challenges of introducing Francis Turbine in Nepalese Micro Hydropower Projects. Journal of Physics: Conference Series, 1266(1), 12007. doi:10.1088/1742-6596/1266/1/012007.

[3] Zaniewski, D., Klimaszewski, P., Witanowski, Ł., Jȩdrzejewski, Ł., Klonowicz, P., \& Lampart, P. (2019). Comparison of an impulse and a reaction turbine stage for an ORC power plant. Archives of Thermodynamics, 40(3), $137-157$. doi:10.24425/ather.2019.129998.

[4] Lampart, P., Witanowski, L., \& Klonowicz, P. (2018). Efficiency optimisation of blade shape in steam and ORC turbines. Mechanics and Mechanical Engineering, 22(2), 553-564. doi:10.2478/mme-2018-0044.

[5] Farriz, M. B., Boejang, H., Masjuri, M., Aras, M. S. M., Razik, N. H. A., Mat, S., \& Sopian, K. (2015). Evolution of simple reaction type turbines for pico-hydro applications. Jurnal Teknologi, 77(32), 1-9. doi:10.11113/jt.v77.6980.

[6] Desai, V. R., \& Aziz, N. M. (1994). An Experimental Investigation of Cross-Flow Turbine Efficiency. Journal of Fluids Engineering, 116(3), 545-550. doi:10.1115/1.2910311.

[7] Hunt, A., Stringer, C., \& Polagye, B. (2020). Effect of aspect ratio on cross-flow turbine performance. Journal of Renewable and Sustainable Energy, 12(5), 054501. doi:10.1063/5.0016753.

[8] Sutikno, D., Soenoko, R., Soeparman, S., \& Wahyudi, S. (2019). The performance characteristics of the low head cross flow turbine using Nozzle Roof curvature radius centered on shaft axis. International Journal of Integrated Engineering, 11(5), 1222. doi:10.30880/ijie.2019.11.05.002.

[9] Sammartano, V., Aricò, C., Carravetta, A., Fecarotta, O., \& Tucciarelli, T. (2013). Banki-Michell optimal design by computational fluid dynamics testing and hydrodynamic analysis. Energies, 6(5), 2362-2385. doi:10.3390/en6052362.

[10] Sammartano, V., Aricò, C., Sinagra, M., \& Tucciarelli, T. (2015). Cross-Flow Turbine Design for Energy Production and Discharge Regulation. Journal of Hydraulic Engineering, 141(3), 04014083. doi:10.1061/(asce)hy.1943-7900.0000977.

[11] Sammartano, V., Filianoti, P., Morreale, G., Sinagra, M., \& Tucciarelli, T. (2016). Banki-Michell micro-turbines for energy production in water distribution networks. Sustainable Hydraulics in the Era of Global Change - Proceedings of the 4th European Congress of the International Association of Hydroenvironment Engineering and Research, IAHR 2016, 966-972. doi:10.1201/b21902-159.

[12] Ceballos, Y. C., Valencia, M. C., Zuluaga, D. H., Del Rio, J. S., \& García, S. V. (2017). Influence of the number of blades in the power generated by a Michell Banki Turbine. International Journal of Renewable Energy Research, 7(4), 1989-1997.

[13] Pokhrel, S. (2017). Computational Modeling of a Williams Cross Flow Turbine, Master's thesis, Wright State University, Ohio, USA.

[14] Planchard, D. (2019). Engineering Design with SOLIDWORKS 2020. SDC Publications, KS, United States.

[15] Ansys Manuals. (2021). A. U. S. Ansys. Inc. Modeling, CFX, Industry-Leading CFD Software, PA, United States. 
[16] Yi, S. S., Htoo, A. M., \& Sein, M. M. (2018). Design of cross flow turbine (runner and shaft). International Journal of Scientific \& Technology Research, 7, 736-40.

[17] Kpordze, C. S. and Warnick, C. (1983). Experience curves for modern low-head Hydroelecric turbines. In Bureau of Reclamation United States Department of the Interior Contract NO. 81-VOlSS, 1-199. Idaho Water and Energy Resources Research Institute University of Idaho, Idaho, United States. 